\title{
The Impact of Knowledge Management Practice on Lean Six Sigma Implementation: The Moderating Role of Human Capital in Health Service Organisations
}

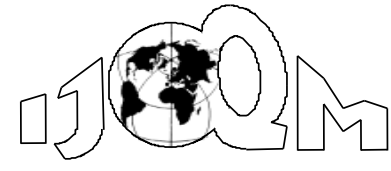

DOI: $10.46970 / 2021.27 .3 .5$

Volume 27, Number 3

September 2021, pp. 267-285

\author{
Sahoum Aljazzazen \\ Roland Schmuck \\ University of Pécs
}

(Eng.sahoum@hotmail.com)

(Schmuck.roland@ktk.pte.hu)

Recently, promoting high-quality healthcare services has become one of the most challenging goals for healthcare systems worldwide. Lean Six Sigma (LSS) is one of the most abundantly adopted improvement initiatives within any organization, including the healthcare sector, gave its capacity in enhancing the organisation's competitive capabilities noting that human capital holds one of the most critical components of its success. This research aims to assess the impact of Knowledge Management (KM) practice on the implementation of LSS with a focus on the moderating role of the human capital in LSS. The study relied on both descriptive and inferential approaches to identify the significance of human capital KM utility on adopting the LSS model. Using a purposive non-probability sampling approach, data were collected using a structured self-administered questionnaire from 467 supervisory and authoritarian level employees operating in five governmental hospitals in Amman, Jordan. The results confirm the significant positive association of $K M$ in the implementation of LSS within an organisation. Regression results indicate that $61.9 \%$ of the variance of LSS implementation can be explained by human capital KM adoption, which was indicated by the $14.1 \%$ increase in the interpretation coefficient $\left(R^{2}\right)$ when the Human capital variable was considered in the model. The novel aspect of this study is to highlight the significance of the inclusion of human capital as a moderating role in LSS implementation.

Keywords: Service Industry, Healthcare, Performance, Continuous Improvement, Knowledge management, Lean, Six Sigma, Jordan

\section{Introduction}

Numerous organizations have adopted Lean Six Sigma as a strategy for improving their competitiveness by increasing both employee and customer satisfaction (Belcher et al., 2018) as well as personality and leadership development of the human capital (Snee, 2010). The success rate of LSS implementation in organizations is often regarded as a challenge with many interconnected affecters (Albliwi et al., 2014). Employees are a critical factor in ensuring the long-term success of LSS initiatives within organizations (Laureani \& Antony, 2016). LSS implementation synthesizes lean and Six Sigma concepts (Chiarini, 2014) to reach 
organisational goals. Overall, LSS's primary objective is to maximize shareholder value by enhancing quality, speed, customer satisfaction, and cost-effectiveness (Antony et al., 2017).

To achieve near-optimal performance results in an organization, employees' KM must be sound as KM aims to ensure that the appropriate knowledge is available to the appropriate people at the proper time to enhance organizational performance (Hubert, 2012).Moreover, it is necessary to consider the possibility that employee competition could obstruct the creation and dissemination of organizational knowledge (Essawi \& Tilchin, 2013). The human nature aspect is one of the most critical elements upon which KM success depends on achieving its goals, as it includes the basis through which knowledge flows within an organization (Rehman et al., 2015). Besides, the human capital factor is a significant aspect of the production process and contributes to the creative processes that lead to the competitive advantage (Bhattacharya et al., 2014).With regards to quality, human capital positively impacts the quality of service organizations provided to customers (Akbari \& Ghaffari, 2017; Qian \& Huang, 2017).

In service industries, about $50 \%$ of processes generate value from the customer's standpoint alone (Michael, 2003). Since LSS was initially designed for the industrial sector, it is scarcely employed in the services sector. Given that the LSS approach applies to a variety of sectors (Kalashnikov et al., 2017);in service sectors, LSS mainly focuses on decreasing waste in time of service processing, as well as reducing variation in the way services are processed and delivered to clients, whether external or internal(Delgado et al., 2010). Numerous hospitals worldwide have incorporated LSS into their operations to lower patient treatment costs and attain continuous improvement in their services (Vaishnavi \& Suresh, 2021). Moreover, LSS has also been used in various hospital settings such as the emergency department (Kalashnikov et al., 2017) and the Cath lab (Agarwal et al., 2016). In that context, Process improvement in an Irish hospital using LSS tools was proven as a highly successful method of initiating process change (Laureani et al., 2013). it was also recognized that applying LSS in hospitals increases quality and cost savings for patients undergoing prosthetic hip replacement surgery (Improta et al., 2015). However, many health institutions -specifically in developing world including the Middle East-suffer from weakness in the application of quality and KM methodologies, especially in the current epidemiological situation (Covid-19). Therefore, this study aimed to verify the impact of the application of knowledge management on achieving the success of applying LSS, and to assess the significance of human capital in doing so.

The paper is organized as follows: The relevant literature on Lean Six Sigma in services is reviewed in section two, followed by the supporting literature in section three. The research methodology, tools, and tests, including reliability tests have been carried out in section four. Data analysis results in section five while the final section presents the conclusion.

\subsection{Knowledge Management}

\section{Literature Review}

Nowadays, organizations are increasingly interested in leveraging KM tools considering it as an effective basis for the processes of creativity and innovation in 
the organization and as a foundation for administrative guidance in achieving efficiency and effectiveness, and outstanding performance (Raudeliūnienè et al., 2018).

According to the researchers and the angles they look through, many definitions are provided to explain the concept of KM. It can be defined as a systematic and organizationally defined process for sharing, transferring, creating, utilizing, and archiving company data to improve organizational performance (Davenport \& Prusak, 1998; Shahzad et al., 2016). KM is also defined as accumulating knowledge and generating it efficiently, facilitating sharing knowledge, and managing its base to be effectively applied in improving the organization (Akbari \& Ghaffari, 2017). Organisations can improve the process of knowledge collection, use, and dissemination to enhance their memory and improve its utility through finding appropriately systematic mechanisms to link workers to knowledge sources (Kordab \& Raudeliūnienè, 2018).

\subsubsection{Knowledge Management Processes}

KM processes are a sequential and complementary series despite the differences between researchers and writers in determining their number and name(Kordab \& Raudeliūnienè, 2018). The four core KM processes identified by (Mertins et al., 2001) include knowledge creation, knowledge storage, knowledge distribution, and knowledge application will be adopted in this work. Brief explanations of each are addressed in the following paragraphs:

Knowledge Creation: As per(Wee \& Chua, 2013), knowledge creation refers to developing new ideas through explicit knowledge interactions between people. The process of acquiring knowledge comprises the organization's ability to extract information and ideas from the external and internal environment (Mills \& Smith, 2011). Therefore, knowledge enters the organisations by enabling employees to learn from external sources, such as developing greater awareness of customer directions (Sangari et al., 2015).

Knowledge Sharing: The term knowledge sharing refers to knowledge distribution, knowledge transfer, and knowledge diffusion (Newman \& Conrad, 2000). Knowledge transfer refers to joint activities with the flow of knowledge from one group to another, including communications, translation, transition, technical aspects, and performance. Most knowledge processes are carried out through communication as it is considered more flexible and easier to move across the organisational units. Knowledge transfer is the first step in implementing knowledge sharing and is concerned with appropriate knowledge to the right person in due time and within a proper cost (Känsäkoski, 2017).

Knowledge Application: This process refers to knowledge use, reuse, and exploitation. The application of knowledge grants both individual and group learning processes that lead to new knowledge creation. Hence, it is often referred to as a closed-loop KM process (Mills \& Smith, 2011). All KM processes are not helpful unless knowledge is put to practical use. Workers must realize that knowledge is 
available and have sufficient freedom to use and apply it, which requires a culture to support learning and change (Chang \& Lin, 2015).

Knowledge Storage: Knowledge storage processes mean those processes that include retention, maintenance, search, access, and retrieval. The storage of knowledge is an important matter, especially for organizations that suffer from high employee turnover rates, as those employees often take their undocumented tacit knowledge with them (Kianto et al., 2016). The process of storing knowledge goes into organizational memory in various forms, including written documents, stored information in electronic databases, human knowledge stored in expert systems as well as knowledge stored in documented organizational procedures and processes (Sangari et al., 2015).

\subsection{Human Capital}

The term human capital was first coined by Gary Baker, an economist at the University of Chicago. Human capital refers to the stock of knowledge and personal characteristics, including creativity and the ability to perform businesses that provide economic value(Alnoor, 2020; Blair, 2011).The concept overall denotes the skills and capabilities that human resources in the company possess to meet any new challenge it faces(Chatterjee, 2017).The human element is an essential element in the success of any sector and at all levels. Without this element, no daily work will be accomplished (Hatch \& Dyer, 2004).

Due to the different views on the definition of human capital, researchers have tried to develop a clear, comprehensive, and unified definition of human capital. Yet, they agree on the essential concept of human capital value. (Murray \& Sharpe, 2011) defined human capital as the accumulated balance of knowledge, experience, qualifications, and innate skills which individuals acquire from education and training. On the other hand, (Pasban \& Nojedeh, 2016) defined it as a set of features, life knowledge, creativity, innovation, and energy emanating from people towards increasing their efficiency and ability to work.

\subsubsection{Dimensions of Human Capital.}

There are many dimensions related to human capital, and the following is a set of dimensions that were employed in the current study

Employee's Knowledge: Successful organizations attach great importance to knowledge and have become the decisive weapon in the organisational competitive race. The knowledge economy sides with the industrial economy and can be the primary key to an organisations' progress, development, and success (Baptista et al., 2014). Employee knowledge is divided into two types; the first is explicit knowledge, which can be expressed in an official language and stored in material means such as documents and archives. The second type is tacit knowledge, which is difficult to put into a formal language because it is latent in individuals' minds (Kordab \& Raudeliūnienè, 2018).

Employee's Skills: Those skills can be defined in our context as the ability of an employee to use his knowledge to complete tasks in the most timely, efficient, and 
effective manner (Cairo \& Cajner, 2018). The skills of employees are divided into two sides; the moral aspect is intangible and is represented in soft skills that are difficult to detect except when absent, such as analysis and reasoning skills, listening skills, engaging in discussions, and problem-solving. The second aspect is the tangible physical aspect, represented in the hard skills, including typing and reading skills, computer literacy, team management, and teamwork (Bhattacharya et al., 2014).

Employee's Experiences: Refers to the accumulated balance of knowledge and skills of an individual or work team through the scientific and practical practice of one or more jobs for a defined period. It is well known that a person acquires knowledge and experiences through situations a person goes through either by reading, watching, listening, or working. The high expertise of the individuals working in the organization is considered a significant resource, as a large part of the work efficiency depends on these experiences (Mubarik, 2015).

Employee Morale: In here we refer to the employee's psychological state and its impact on his behavior, attitude, emotional desire to work as defined by (Hiean et al., 2018). If the morale of the individual is high, this will be reflected in his enthusiasm. Therefore, it will increase interest in his work and innovation potential through increasing his sense of belonging to the company leading to linking his personal goals with organizational goals (Chow et al., 2007).

\subsection{Lean Six Sigma (LSS)}

LSS is a synergy of Six Sigma and Lean Manufacturing, incorporating principles and concepts from both (Coronado \& Antony, 2002; Laureani \& Antony, 2017). Academic discussions have erupted around the combination of Lean and Six Sigma(Antony et al., 2017); Six Sigma's success is founded on applying statistical tools for identifying flaws and optimizing processes while also responding to consumer feedback(Sharma \& Chetiya, 2009). Moreover, Six Sigma is a methodology for optimizing business processes through an understanding of and control over variation and a reduction in the cost of poor-quality services or products (Kanji, 2008; Srinivasan et al., 2016). In that sense, KM is an integral part of LSS.

Additionally, while LM provides a library of conventional answers to common problems and optimizes operations and value chains where it lacks organizational structure, analytical tools, and quality control (de Koning et al., 2006). Organisations face the most challenging difficulties when it comes to excess and waste of processes and their outputs. Waste mainly is implied in resources, time, personnel, and capital. In today's business environment, businesses often rely on cutting expenses to offer more affordable and high-quality services. Cost savings are possible if an organization takes a systematic approach to waste (Ferguson, 2007). According to LM discourse, quality improvement can be accomplished by limiting any process within the organization that does not contribute to the value (Cooper \& Edgett, 2008). Today, most organizations have embraced one of those two ways to boost competitiveness.

Apart from the Lean manufacturing favorable outcomes, it cannot bring a process under statistical control, and Six Sigma alone cannot significantly increase 
production speed and decrease invested capital (Carreira, 2005). As a result, combining the two procedures is necessary (Arnheiter \& Maleyeff, 2005) and may decrease process variation while increasing waste elimination (Jing, 2009). In this regard, the LSS concept arose as a combination of the two concepts, seeking to integrate their functionalities and add value to enterprises (Arnheiter \& Maleyeff, 2005). LSS integrates Six Sigma and Lean manufacturing processes, with Lean focusing on cycle time and waste elimination and Six Sigma on defect elimination and variation reduction (Lubowe \& Blitz, 2008).

The failure rate or long-term viability of LSS efforts is another significant issue for enterprises (Albliwi et al., 2014). If sustained performance from the interplay of employees and technical systems is required, an organization must balance employees' efficiency and psychosocial demands (Soliman \& Saurin, 2017). Additionally, employee communication inside the organization is critical for the success of LSS. Whether it is official or informal (Spasojevic Brkic \& Tomic, 2016). Employee training and continuous education are also essential for LSS adoption. At least three years of training on all levels are expected to be necessary for the successful implementation of LSS (Sony \& Mekoth, 2019).

LSS has been used successfully in manufacturing and, in some situations, in services, increasing procedure efficiency and product quality (Engelund et al., 2009). Deploying LSS entails more than simply implementing tools or procedures; it entails establishing a culture of waste elimination, variation reduction, and continual improvement (Antony et al., 2017). Businesses can improve their business environment and thus their performance by applying this practice. Not every employee will fit into this new workplace. As a result, the alignment of individual and corporate culture is critical (O'Reilly III et al., 1991). Consequently, implementing LSS would require staff to adjust to various new characteristics of the organisation's new environment. Moreover, LSS is a quality-driven and continuous improvement-oriented approach that relies on participation and knowledge sharing among all employees (Lubowe \& Blitz, 2008).

For LSS implementation, the employee is required to acquire new skills, technologies, and procedures, among other things. LSS ensures that an organisation's employees are constantly learning (Albliwi et al., 2014). As a result, employees must priorities learning new tasks, procedures, and skills. However, for that to happen, employees must first acquire statistical knowledge and apply it in the workplace. Organisations management must develop an effective training program to accept these new skills. A poorly trained employee can jeopardize LSS initiatives (Arnheiter \& Maleyeff, 2005). Continuous improvement instills a sense of responsibility in everyone to be lean and improve. Thus, for LSS initiatives to be successful, employees must adapt to learning new tasks, technologies, sciences, and procedures.

\section{Methodology}

A Research methodology is defined as a set of rules and regulations that are made to help arrive at acceptable and logical facts about the problem of interest or study (Kumar, 2018).This study relied on both descriptive and inferential approaches to identify the impact of KM on applying the LSS methodology, through the moderating role of human capital. This approach is based on an accurate and 
detailed interpretation of the problem by defining its conditions, components, and dimensions by analysing, measuring, and interpreting data. Therefore, arriving at an accurate description of the phenomenon or problem holistically is useful in generalizing the knowledge that has been extracted and helps achieve a sufficient level of prediction (Sekaran \& Bougie, 2019).Multiple linear regression, as well as hierarchal linear regression, were employed to identify the best model and significant variables that explain LSS implementation. Results were considered statistically significant at the level of $(\alpha \leq 0.05)$.

\subsection{Data Sources}

In Jordan, there are (31) government hospitals, (15) military hospitals, (2) university hospitals, and (69) private hospitals, with a total of (117) hospitals providing services in various medical specialties for patients. According to the Ministry of Health report for the year (2021), the number of government hospitals in the capital, Amman, is (5) hospitals, namely (Al-Bashir, Jamil Al-Totanji, AlKarama, Prince Hamzah, the National Center for the Rehabilitation of Addicts), in which approximately $(4,677)$ employees work under the MOH supervisory and control authorities (MOH, 2021). An Online questionnaire was distributed to those hospitals using simple random sampling method utilising Google Forms. (397) valid questionnaire responses were received and employed. In collecting the primary data, the study relied on a questionnaire developed in proportion to the study variables, and the study relied on the Five Likert Scale.In addition to using the above questionnaire for primary data, the study relied on secondary data such from books, publications, scientific periodicals, and specialised publications. The electronic resources available on the internet and the various databases that served the study were also used.

\subsection{Study Variables}

The arithmetic means, standard deviations, rank, relative weight, and approval degree were calculated to determine the sample members' opinions on the study variables. The degree of relative weight was determined according to the following equation: Category length $=$ (the upper limit of the alternative - the lower limit of the alternative) $/$ number of levels (i.e. category length $=(5-1) / 3=1.33$. As per (Subedi, 2016); if the arithmetic mean falls between (1-2.33), it is considered as a low level. On the other hand, if it ranges between (2.34-3.66), it falls within the medium level, while If it exceeds (>3.66), it is considered within the high level. The data descriptive of the study variables are as shown in Table 1:

The results displayed in Table (1) demonstrate that the independent variable (KM) falls under the highest range with an arithmetic mean of (4.04), relative weight of $(80.8 \%)$, a standard deviation of (0.501), and a high degree of approval. Knowledge creation ranked as the second-highest range with an arithmetic mean value of (4.07), a relative weight $(81.4 \%)$, a standard deviation (0.597), and a high degree of agreement. Knowledge storage was ranked the third-highest range with an arithmetic mean of (4.06), a relative weight of (81.2\%), a standard deviation (0.587), and a high degree of approval. Knowledge application was ranked fourth with an arithmetic mean of (4.02), a relative weight of (80.4\%), a standard deviation of (0.605) and a high degree of approval. As for knowledge sharing, it came in fifth place with an 
arithmetic mean of (4.01), a relative weight of (80.2\%), a standard deviation of (0.556), and a high degree of approval.

Table 1 Descriptive Statistics

\begin{tabular}{|l|l|c|c|c|l|}
\hline Variable type & \multicolumn{1}{|c|}{ Variable } & Mean & S.D & Relative weight & Agreement degree \\
\hline \multirow{5}{*}{ Independent } & Knowledge Creation & 4.07 & 0.597 & $\% 81.4$ & High \\
\cline { 2 - 6 } & Knowledge Sharing & 4.01 & 0.556 & $\% 80.2$ & High \\
\cline { 2 - 6 } & Knowledge Application & 4.02 & 0.605 & $\% 80.4$ & High \\
\cline { 2 - 6 } & Knowledge Storage & 4.06 & 0.587 & $\% 81.2$ & High \\
\cline { 2 - 6 } & Knowledge Management & 4.04 & 0.501 & $\% 80.8$ & High \\
\hline \multirow{5}{*}{ Dependent } & Implementation LSS & 3.93 & 0.533 & $\% 78.6$ & High \\
\hline & Employee's Knowledge & 3.95 & 0.564 & $\% 79$ & High \\
\cline { 2 - 6 } & Employee's Experiences & 3.97 & 0.549 & $\% 79.4$ & High \\
\cline { 2 - 6 } & Employee's Skills & 4.04 & 0.585 & $\% 80.8$ & High \\
\cline { 2 - 6 } & Employee's Morals & 4.04 & 0.596 & $\% 80.8$ & High \\
\cline { 2 - 6 } & Human capital & 4.00 & 0.491 & $\% 80$ & High \\
\hline
\end{tabular}

The dependent variable, the LSS implementation, achieved an arithmetic mean of (3.93), a relative weight of (78.6\%), a high degree of approval, and a standard deviation of (0.533). The adjusted variable human capital achieved an arithmetic mean of (4), with a relative weight of $(80 \%)$, a high degree of approval, and a standard deviation of (0.491). Employees' skills was ranked the first with a mean of (4.04) and a relative weight $(80.8 \%)$ and a high degree of approval, and with a standard deviation of (0.585), and employees' morale in the second place with arithmetic mean of (4.04) and a relative weight of (80.8\%). Employees' experiences came in third place with an arithmetic mean of (3.97) and a relative weight of (79.4\%), a high degree of approval, and a standard deviation of (0.549). Employees' knowledge came in fourth place with an arithmetic mean of (3.95) and a relative weight of $(79 \%)$, with a high degree of agreement and a standard deviation of (0.564). We note that the standard deviations of all dimensions are close to each other indicating a lack of dispersion in the answers of the study sample members towards the study measurement items.

\subsection{Reliability}

The study relied on the Cronbach's Alpha coefficient in aligning the stability and internal consistency of the study variables as shown in Table 2.

It is clear from Table (2) that the value of the internal consistency coefficient (Cronbach Alpha) for the items of the study instrument ranged between $(74.2 \%$ $89.4 \%$ ) with a stability degree of $(94.7 \%)$ for all items. (Sekaran \& Bougie, 2019: $325)$ suggested that the minimum accepted stability coefficient is $(0.70)$. The closer the value is to one, the higher the degrees of stability for the study instrument. The internal consistency mentioned in the above table is a good indicator of the study instrument's strength and reliability in statistical analysis. 
Table 2 The Value of the Coefficient (Cronbach Alpha)

\begin{tabular}{|l|c|c|c|c|c|c|c|c|c|c|c|c|}
\hline $\begin{array}{l}\text { Varia } \\
\text { bles }\end{array}$ & $\begin{array}{c}\text { K. } \\
\text { Creat } \\
\text { ion }\end{array}$ & $\begin{array}{c}\text { Kh. } \\
\text { Sha } \\
\text { ng }\end{array}$ & $\begin{array}{l}\text { K. } \\
\text { Appli } \\
\text { cation }\end{array}$ & $\begin{array}{c}\text { K. } \\
\text { Storg }\end{array}$ & $\mathbf{~ K M}$ & $\begin{array}{c}\text { LSS } \\
\text { imple } \\
\text { menta } \\
\text { tion }\end{array}$ & $\begin{array}{c}\text { E. } \\
\text { Know } \\
\text { ledge }\end{array}$ & $\begin{array}{c}\text { E. } \\
\text { Exper } \\
\text { ience }\end{array}$ & $\begin{array}{c}\text { E. } \\
\text { Skills }\end{array}$ & $\begin{array}{c}\text { E. } \\
\text { Moral } \\
\text { S }\end{array}$ & $\begin{array}{c}\text { Huma } \\
\mathbf{n} \\
\text { Capit } \\
\text { al }\end{array}$ & $\begin{array}{c}\text { T. } \\
\text { Indic } \\
\text { ator }\end{array}$ \\
\hline $\begin{array}{l}\text { Cron } \\
\text { bach } \\
\text { Alpha }\end{array}$ & 0.833 & 0.756 & 0.831 & 0.742 & 0.894 & 0.857 & 0.773 & 0.813 & 0.787 & 0.781 & 0.874 & $\mathbf{0 . 9 4 7}$ \\
\hline $\begin{array}{l}\text { N. of } \\
\text { items }\end{array}$ & 3 & 3 & 3 & 3 & $\mathbf{1 2}$ & $\mathbf{7}$ & 3 & 3 & 3 & 3 & $\mathbf{1 2}$ & $\mathbf{3 1}$ \\
\hline
\end{tabular}

\subsection{Construct Validity}

Structural validity measures the extent to which the utilized tool can reach and whether it can measure the content for which it was designed. The correlation coefficient (Pearson Correlation) shows the correlation of each instrument item with the total degree of its axis. Negative paragraphs or whose correlation coefficient is less than (0.25) are considered low, and it is advised to exclude them from the following models (Miller et al., 2013: 136). Table (3) shows the results of structural validity for our tool.

Table 3 The Correlation Degrees of the Scale Items with their Axis

\begin{tabular}{|c|c|c|c|c|c|c|c|}
\hline \multicolumn{8}{|c|}{ Independent Variable: KM } \\
\hline \multirow{2}{*}{ Knowledge generation } & \multicolumn{2}{|l|}{ Item } & 1 & \multicolumn{2}{|r|}{2} & \multicolumn{2}{|r|}{3} \\
\hline & $\mathrm{R}$ & & 0.873 & & 0.891 & & 0.837 \\
\hline \multirow{2}{*}{ Knowledge sharing } & Item & & 4 & & 5 & & 6 \\
\hline & $\mathrm{R}$ & & 0.841 & & 0.842 & & 0.776 \\
\hline \multirow{2}{*}{ Knowledge application } & Item & & 7 & & 8 & & 9 \\
\hline & $\mathrm{R}$ & & 0.860 & & 0.883 & & 0.854 \\
\hline \multirow{2}{*}{ Knowledge storge } & Item & & 10 & & 11 & & 12 \\
\hline & $\mathrm{R}$ & & 0.836 & & 0.813 & & 0.793 \\
\hline \multicolumn{8}{|c|}{ Dependent Variable: LSS } \\
\hline Item & 1 & 2 & 3 & 4 & 5 & 6 & 7 \\
\hline $\mathbf{R}$ & 0.766 & 0.767 & 0.784 & 0.744 & 0.713 & 0.649 & \begin{tabular}{l|l}
9 & 0.723
\end{tabular} \\
\hline \multicolumn{8}{|c|}{ Moderating Variable: Human Capital } \\
\hline \multirow{2}{*}{ Employee's Knowledge } & Item & & 1 & & 2 & & 3 \\
\hline & $\mathrm{R}$ & & 0.847 & & 0.841 & & 0.801 \\
\hline \multirow{2}{*}{ Employee's experiences } & Item & & 4 & & 5 & & 6 \\
\hline & $\mathrm{R}$ & & 0.844 & & 0.853 & & 0.863 \\
\hline \multirow{2}{*}{ Employee's skills } & Item & & 7 & & 8 & & 9 \\
\hline & $\mathrm{R}$ & & 0.850 & & 0.873 & & 0.799 \\
\hline \multirow{2}{*}{ Employee's morals } & Item & & 10 & & 11 & & 12 \\
\hline & $\mathrm{R}$ & & 0.841 & & 0.855 & & 0.815 \\
\hline
\end{tabular}


We note from Table (3) that the correlation value coefficient for all items of the scale exceeds $(25 \%)$ with all bearing a positive $(+)$ value. This validated that the instrument variables are structurally valid.

\subsection{Normality Tests}

To measure the results distribution normality, skewness and kurtosis were calculated; a skewness value outside the range of $( \pm 1)$ indicates that the distribution is highly skewed. On the other hand, the distribution is considered normal if the kurtosis value does not exceed \pm 2.58 (at the p level of 0.01 ) and \pm 1.96 (at the level of 0.05 ) (Hair et al., 2018:76). In our work, we adopt the $95 \%$ confidence interval. Results are shown in

Table 4 Skewness \& Kurtosis - Normality Tests

\begin{tabular}{|c|c|c|c|c|c|c|c|c|c|c|c|}
\hline $\begin{array}{c}\text { Variabl } \\
\text { es }\end{array}$ & $\begin{array}{c}\text { K. } \\
\text { Creati } \\
\text { on }\end{array}$ & $\begin{array}{c}\text { K. } \\
\text { Shari } \\
\text { ng }\end{array}$ & $\begin{array}{c}\text { K. } \\
\text { Applicati } \\
\text { on }\end{array}$ & $\begin{array}{c}\text { K. } \\
\text { Stora } \\
\text { ge }\end{array}$ & $\begin{array}{c}\text { K. } \\
\text { managem } \\
\text { ent }\end{array}$ & $\begin{array}{c}\text { LSS } \\
\text { Implementat } \\
\text { ion }\end{array}$ & $\begin{array}{c}\text { E. } \\
\text { Knowled } \\
\text { ge }\end{array}$ & $\begin{array}{c}\text { E. } \\
\text { Experien } \\
\text { ce }\end{array}$ & $\begin{array}{c}\text { E. } \\
\text { Skii } \\
\text { ls }\end{array}$ & $\begin{array}{c}\text { E. } \\
\text { Mora } \\
\text { Is }\end{array}$ & $\begin{array}{c}\text { Hum } \\
\text { an } \\
\text { Capit } \\
\text { al }\end{array}$ \\
\hline $\begin{array}{c}\text { Skewnes } \\
\mathbf{s}\end{array}$ & -0.503 & -0.250 & -0.305 & -0.290 & $\mathbf{- 0 . 2 4 3}$ & $\mathbf{- 0 . 2 2 2}$ & -0.053 & 0.046 & 0.17 & -0.210 & $-\mathbf{0 . 0 6 7}$ \\
\hline Kurtosis & 0.547 & 0.720 & -0.072 & -0.081 & $\mathbf{0 . 4 0 2}$ & $\mathbf{- 0 . 2 8 6}$ & -0.349 & -0.192 & 0.21 & -0.228 & $-\mathbf{- 0 . 3 2 9}$ \\
\hline
\end{tabular}

Based on the normality test results shown in Table (4), it is clear that the data is normally distributed, as the skewness values did not fall outside the range $( \pm 1)$ and kurtosis did not exceed the value of $( \pm 1.96)$ at the level $(\mathrm{p}<0.05)$. This confirms the validity of our statistical analysis and modeling.

\subsection{Multicollinearity}

The Variance Inflation Factor (VIF) and Tolerance were calculated to assess multicollinearity within our variables. After performing the statistical treatment, the results obtained and shown in Table (5) reveal that the values of the VIF were all less than (5) which is below the permissible coefficient of variation of (1) and greater than (0.2). This demonstrates that there is no collinearity between the independent variables, which indicates that the values are accepted and suitable for conducting multiple linear regression analysis (Hair et al., 2018:200).

Table 5 Multicollinearity Test

\begin{tabular}{|l|c|c|}
\hline Knowledge Management & VIF & Tolerance \\
\hline Knowledge Creation & 2.117 & 0.472 \\
\hline Knowledge Sharing & 2.303 & 0.434 \\
\hline Knowledge Usage & 2.370 & 0.422 \\
\hline Knowledge Storage & 2.065 & 0.484 \\
\hline
\end{tabular}


To confirm the previous results, Pearson correlation coefficients between the dimensions of the study were measured to ensure that there were no high correlations between the independent variables; Table (6) presents the results obtained.

Table 6 Correlation Matrix (Pearson) for Independent Variables

\begin{tabular}{|l|c|c|c|c|}
\hline \multicolumn{1}{|c|}{ Variables } & $\begin{array}{c}\text { Knowledge } \\
\text { Creation }\end{array}$ & $\begin{array}{c}\text { Knowledge } \\
\text { Sharing }\end{array}$ & $\begin{array}{c}\text { Knowledge } \\
\text { Usage }\end{array}$ & $\begin{array}{c}\text { Knowledge } \\
\text { Storage }\end{array}$ \\
\hline $\begin{array}{l}\text { Knowledge } \\
\text { Creation }\end{array}$ & 1.00 & 1.00 & & \\
\hline $\begin{array}{l}\text { Knowledge } \\
\text { Sharing }\end{array}$ & 0.673 & 0.664 & 1.00 & \\
\hline $\begin{array}{l}\text { Knowledge } \\
\text { Usage }\end{array}$ & 0.624 & 0.603 & 0.674 & 1.00 \\
\hline $\begin{array}{l}\text { Knowledge } \\
\text { Storage }\end{array}$ & 0.588 & & & \\
\hline
\end{tabular}

The results presented in Table (6) demonstrate that the highest correlation between the independent variables is (0.674) namely between knowledge storage and usage. All other variables ranged between $(0.588-0.673)$. This indicates that there was no high correlation between the independent variables, where the values were less than $(80 \%)$; therefore, the sample is free from the problem of high correlation (Gujarati \& Porter, 2011).

\section{Results}

In this section, we present the results from multiple linear regression analysis, followed by hierarchical regression analysis.

\subsection{Multiple Linear Regression}

The results presented in Table (7) show that there is a statistically significant effect of $\mathrm{KM}$ in the LSS implementation, which appears through the value of (F. Sig = $0.00)$ as well as the calculated $(\mathrm{F})$ value (158.918), which is greater than its tabular value (2.37). The models predict a strong correlation between KM and the implementation of the LSS methodology. the predictability power $\left(\mathrm{R}^{2}=0.619\right)$ indicates that $(61.9 \%)$ of the variance was able to be explained by KM for the LSS implementation, which leaves $(38.1 \%)$ which correspond to variables that were not included in the study model. The coefficients table results show that knowledge storage had the most significant impact on the dependent variable (i.e.LSS implementation), as the value of its beta coefficient was $(\beta=0.488)$. This effect is reinforced by the calculated and equal $\mathrm{T}$ value of 10.882 , which is greater than its tabular value of $(1.96)$, and with a significant level $(\mathrm{Sig}=0.00)$. Knowledge creation came in second place in terms of impact as the value of its beta coefficient reached $(\beta=0.196)$. This effect is confirmed by the value of $(T=4.326)$, which is greater than its tabular value and at a significant level $(\mathrm{Sig}=0.00)$. Knowledge sharing came in third place in terms of impact as the value of its beta coefficient reached $(\beta=$ $0.114)$, and this effect is reinforced by the calculated $(T=2.409)$, which is greater than its tabular value and at a significant level ( $\mathrm{Sig}=0.016)$. Finally, knowledge usage ranked fourth and last in terms of the effect where the value of its beta coefficient reached $(\beta=0.103)$. This effect is reinforced by $(T=2.144)$, greater than its tabular value and at a significant level ( $\mathrm{Sig}=0.033)$. Consequently, it was proven 
that there is a statistically significant effect at the level $(\alpha \leq 0.05)$ of KM on the LSS implementation in Jordanian government hospitals.

Table 7 Multiple Linear Regression Model Results

\begin{tabular}{|c|c|c|c|c|c|c|c|c|c|c|c|}
\hline \multicolumn{3}{|c|}{ Model Summery } & \multicolumn{3}{|c|}{ ANOVA } & \multicolumn{6}{|c|}{ Coefficient } \\
\hline $\mathbf{R}$ & $\mathbf{R}^{2}$ & Adj. $\mathbf{R}^{2}$ & $\mathbf{F}$ & F.Sig & DF & Variables & B & Std. Error & Beta & $\mathbf{T}$ & Sig \\
\hline \multirow{4}{*}{$0.786 \mid$} & \multirow{4}{*}{0.619} & \multirow{4}{*}{0.615} & \multirow{4}{*}{158.918} & \multirow{4}{*}{0.00} & \multirow{4}{*}{$392 / 4$} & Knowledge Creation & 0.175 & 0.041 & 0.196 & 4.326 & 0.00 \\
\hline & & & & & & Knowledge Sharing & 0.109 & 0.045 & 0.114 & 2.409 & 0.016 \\
\hline & & & & & & Knowledge Application & 0.091 & 0.042 & 0.103 & 2.144 & 0.033 \\
\hline & & & & & & Knowledge Storge & 0.443 & 0.041 & 0.488 & 10.882 & 0.00 \\
\hline
\end{tabular}

\subsection{Hierarchal Regression}

Hierarchal linear regression results provided in table (8) indicate that in the first model, the impact of KM on the implementation of the LSS in Jordanian government hospitals was significant at $(\alpha \leq 0.05)$ with an $F$ value of $(551.288)$. Hence the Beta value (0.763) and the $T$ value is equal to (23.480) which indicates that in the first model KM explains (58.3\%) of the variance in applying LSS. In the second model, the human capital variable was introduced and added to the model to assess its impact on implementing LSS. It was found that there was a significant effect of human capital on the implementation of the LSS $(\alpha \leq 0.05)$ with an F value of (463.772) and a beta coefficient value of (Beta $=0.500)$ with a $\mathrm{T}$ value equal to (12.555). It appears from the second model that the addition of the human capital variable has led to an increase in the model's predictability $\left(\mathrm{R}^{2}=11.9 \%\right)$ compared to the first model. In the third model, the binary interaction formula was introduced and added between KM and human capital. It was found that there is a significant effect on the LSS implementation in Jordanian government hospitals. The F value of the binary interaction reached (343.169), the Bata value (0.459), and the T value (5.577), which is significant at the level of $(\alpha \leq 0.05)$. The interpretation coefficient (R2) was further enhanced compared to both the first and third models. Accordingly, it can be said that the human capital variable has a significant moderating role in the relationship between KM and the implementation of LSS.

Table 8 Results of the Second Main Hypothesis Test

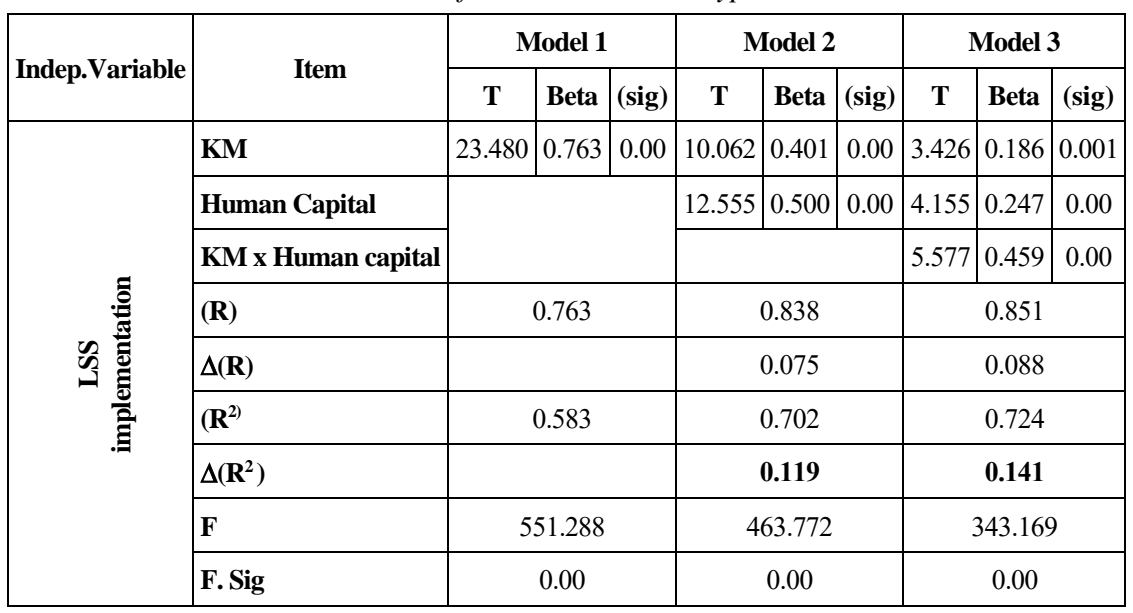




\section{Discussion}

This study's results agree with (Pinjari \& Teli, 2018) study, which confirms that KM is crucial in this heavily based knowledge information sector. Consequently, the organization requires the maintenance of employees' specialised technical knowledge and problem-solving skills to maintain the organisation's smooth operation. Technical expertise must be mastered, and tacit knowledge must be improved through continuous training and experience. Specialist expertise includes performing procedural knowledge, such as LSS problem-solving procedural knowledge training (Albliwi et al., 2014).

One important practice for KM implementation in LSS is proper knowledge implementation as in providing interactive module notations and training manuals, having top executives deliver an opening speech as well as teaching using innovative theoretical approaches. While for best practices of KM in LSS, the idea revolves around knowledge creation through brainstorming and daily performance reviews. Additionally, the importance of knowledge storage arises in indexing knowledge in easily usable forms and standardized formats, leveraging the utility of stored knowledge to employees (Muhammad \& Chin, 2020). Moreover, without proper, regular application of the human capital knowledge, skills, and experience during the LSS training, human capital's acquired skills would be lost within months. Whole organisational involvement is required to successfully complete KM implementation in LSS. Furthermore, utilizing LSS knowledge enables the creation of new knowledge for problem-solving and continuous improvement (Sin et al., 2015; Zhang \& Chen, 2016).

Employee capabilities and attitudes are critical to the success of lean efforts (Worley \& Doolen, 2006). The most crucial necessity for LSS is proper training and communication among employees (Laureani \& Antony, 2016). Additionally, employees must sufficiently understand their responsibilities and the what, how, and proper order of tasks (Pepper \& Spedding, 2010). Although six sigma training is critical to its success, it is believed to be prohibitively both expensive and timeconsuming (Ranjan Senapati, 2004).This can be attributed to the fact it is not yet standardised leading to its efficacy being questioned. Similarly, employee responsibilities play a part in the success of LSS (Spasojevic Brkic \& Tomic, 2016). In the absence of a general framework for implementing LSS (Pepper \& Spedding, 2010); employee roles become even more crucial. Additionally, the installation of LSS dynamically changes the duties of individual employees, their assignments, work organizations, employment relationships, tasks, and activities (Drotz \& Poksinska, 2014).

\section{Conclusion}

This study aimed to examine the impact of the KM practice on the success of applying the LSS methodology, and to examine the extent of the impact of human capital in moderating the relationship between KM and LSS. The study results show that there is a significant impact of KM on the LSS implementation. The interpretation coefficient $\left(\mathrm{R}^{2}\right)$ increased by $14.1 \%$ when adding human capital as additional variable to the model. Human capital is critical to the success of LSS since they implement the LSS initiatives. The success or failure of LSS programs is 
determined by how well employees adapt to LSS standards, and how well they learn the basis for its implementation. Both KM and LSS are quickly infiltrating business management systems with problem-solving and process-optimization methodologies after realising huge gains could be made if the tools of KM were applied. The main contribution of this study is that it is considered a base for future research that deals with two critical topics in applying LSS (i.e. knowledge management, and human capital). The researcher recommends conducting more studies by taking private hospitals and medical centers, and future research can employ more KM and human capital dimensions.

One of the study's limitations is the scarcity of studies that dealt with the impact of KM on the LSS implementation while incorporating the human capital dimension which can have an impact on results comparability. Another limitation of this study is that it was applied to a specific segment of hospitals within a particular geographical area, i.e. governmental hospitals in Amman, Jordan.

\section{References}

1. Agarwal, S., Gallo, J. J., Parashar, A., Agarwal, K. K., Ellis, S. G., Khot, U. N., Spooner, R., Murat Tuzcu, E., \& Kapadia, S. R. (2016). Impact of lean six sigma process improvement methodology on cardiac catheterization laboratory efficiency. Cardiovascular Revascularization Medicine, 17(2), 95-101. https://doi.org/10.1016/j.carrev.2015.12.011

2. Akbari, N., \& Ghaffari, A. (2017). Verifying relationship of knowledge management initiatives and the empowerment of human resources. Journal of Knowledge Management.

3. Albliwi, S., Antony, J., Abdul Halim Lim, S., \& van der Wiele, T. (2014). Critical failure factors of Lean Six Sigma: a systematic literature review. International Journal of Quality \& Reliability Management, 31(9), 1012-1030. https://doi.org/10.1108/ijqrm-09-2013-0147

4. Alnoor, A. (2020). Human capital dimensions and firm performance, mediating role of knowledge management. International Journal of Business Excellence, 20(2), 149-168.

5. Antony, J., Snee, R., \& Hoerl, R. (2017). Lean Six Sigma: yesterday, today and tomorrow. International Journal of Quality \& Reliability Management, 34(7), 1073-1093. https://doi.org/10.1108/ijqrm-03-2016-0035

6. Arnheiter, E. D., \& Maleyeff, J. (2005). The integration of lean management and Six Sigma. The TQM Magazine, 17(1), 5-18. https://doi.org/10.1108/09544780510573020

7. Baptista, R., Karaöz, M., \& Mendonça, J. (2014). The impact of human capital on the early success of necessity versus opportunity-based entrepreneurs. Small Business Economics, 42(4), 831-847.

8. Belcher, J., Kaldas, E., Ellington, V. B., \& Davè, D. S. (2018). Developing a quality improvement plan for a small engineering firm in the USA with Six Sigma methodologies. International Journal of Productivity and Quality Management, 24(1), 1. https://doi.org/10.1504/ijpqm.2018.091169

9. Bhattacharya, M., Harold Doty, D., \& Garavan, T. (2014). The organizational context and performance implications of human capital investment variability. Human Resource Development Quarterly, 25(1), 87-113. 
10. Blair, M. M. (2011). An economic perspective on the notion of 'human capital.' In The Oxford handbook of human capital.

11. Cairo, I., \& Cajner, T. (2018). Human capital and unemployment dynamics: Why more educated workers enjoy greater employment stability. The Economic Journal, 128(609), 652-682.

12. Carreira, B. (2005). Lean manufacturing that works: powerful tools for dramatically reducing waste and maximizing profits. AMACOM/American Management Association.

13. Chang, C. L., \& Lin, T.-C. (2015). The role of organizational culture in the knowledge management process. Journal of Knowledge Management.

14. Chatterjee, J. (2017). Strategy, human capital investments, business-domain capabilities, and performance: a study in the global software services industry. Strategic Management Journal, 38(3), 588-608.

15. Chiarini, A. (2014). A comparison between time-driven activity-based costing and value stream accounting in a lean Six Sigma manufacturing case study. International Journal of Productivity and Quality Management, 14(2), 131. https://doi.org/10.1504/ijpqm.2014.064472

16. Chow, C. W., Haddad, K., \& Singh, G. (2007). Human resource management, job satisfaction, morale, optimism, and turnover. International Journal of Hospitality \& Tourism Administration, 8(2), 73-88.

17. Cooper, R. G., \& Edgett, S. J. (2008). Maximizing productivity in product innovation. Research-Technology Management, 51(2), 47-58.

18. Coronado, R. B., \& Antony, F. (2002). Critical success factors for the successful implementation of six sigma projects in organisations. TQM Magazine, 14(2), 92-99. https://doi.org/10.1108/09544780210416702

19. Davenport, T. H., \& Prusak, L. (1998). Working knowledge: How organizations manage what they know. Harvard Business Press.

20. de Koning, H., Verver, J. P. S., van den Heuvel, J., Bisgaard, S., \& Does, R. J. M. M. (2006). Lean Six Sigma in Healthcare. Journal for Healthcare Quality, 28(2), 4-11. https://doi.org/10.1111/j.1945-1474.2006.tb00596.x

21. Delgado, C., Ferreira, M., \& Castelo Branco, M. (2010). The implementation of lean Six Sigma in financial services organizations. Journal of Manufacturing Technology Management, 21(4), 512-523. https://doi.org/10.1108/17410381011046616

22. Drotz, E., \& Poksinska, B. (2014). Lean in healthcare from employees' perspectives. Journal of Health Organization and Management, 28(2), 177-195. https://doi.org/10.1108/jhom-03-2013-0066

23. Engelund, E. H., Breum, G., \& Friis, A. (2009). Optimisation of large-scale food production using Lean Manufacturing principles. Journal of Foodservice, 20(1), 4-14.

24. Essawi, M., \& Tilchin, O. (2013). A model of knowledge management culture change.

25. Ferguson, D. (2007). Lean and Six Sigma: The same or different. Management Services, 51(3), 12-13.

26. Gujarati, D., \& Porter, D. (2011). Basic Econometrics. (5th Ed.). The Mc Graw Hill. 
27. Hair, Joseph F; Babin, Barry J.; Anderson, Rolph E.; Black, W. C. (2018). Multivariate Data Analysis (8th ed.). Cengage Learning EMEA.

28. Hatch, N. W., \& Dyer, J. H. (2004). Human capital and learning as a source of sustainable competitive advantage. Strategic Management Journal, 25(12), 1155-1178.

29. Hiean, T. K., Samah, I. H., Abashah, A., Nurshahrizleen, S., \& Muhammad, N. (2018). Factor of vendor selection and employees' morale towards human resource outsourcing decision in organization. MATEC Web of Conferences, $150,5019$.

30. Hubert, C. (2012). The New Edge In Knowledge: How Knowledge Management Is Changing The Way We Do Business. In All Days. OTC. https://doi.org/10.4043/23620-ms

31. Improta, G., Balato, G., Romano, M., Carpentieri, F., Bifulco, P., Alessandro Russo, M., Rosa, D., Triassi, M., \& Cesarelli, M. (2015). L ean S ix S igma: a new approach to the management of patients undergoing prosthetic hip replacement surgery. Journal of Evaluation in Clinical Practice, 21(4), 662-672.

32. Jing, G. G. (2009). A lean six sigma breakthrough. Quality Progress, 42(5), 2431.

33. Kalashnikov, V., Benita, F., López-Ramos, F., \& Hernández-Luna, A. (2017). Bi-objective project portfolio selection in Lean Six Sigma. International Journal of Production Economics, 186, 81-88. https://doi.org/10.1016/j.ijpe.2017.01.015

34. Kanji, G. K. (2008). Reality check of Six Sigma for Business Excellence. Total Quality Management \& Business Excellence, 19(6), 575-582. https://doi.org/10.1080/14783360802024333

35. Känsäkoski, H. (2017). Information and knowledge processes as a knowledge management framework in health care: Towards shared decision making? Journal of Documentation.

36. Kianto, A., Vanhala, M., \& Heilmann, P. (2016). The impact of knowledge management on job satisfaction. Journal of Knowledge Management.

37. Kordab, M., \& Raudeliūnienè, J. (2018). Knowledge management cycle: a scientific literature review. 10th International Scientific Conference „Business and Management 2018 “.

38. Kumar, R. (2018). Research methodology: A step-by-step guide for beginners. Sage.

39. Laureani, A., \& Antony, J. (2016). Leadership - a critical success factor for the effective implementation of Lean Six Sigma. Total Quality Management \& Business $\quad$ Excellence, 29(5-6), 502-523. https://doi.org/10.1080/14783363.2016.1211480

40. Laureani, A., \& Antony, J. (2017). Leadership and Lean Six Sigma: a systematic literature review. Total Quality Management \& Business Excellence, 30(1-2), 53-81. https://doi.org/10.1080/14783363.2017.1288565

41. Laureani, A., Brady, M., \& Antony, J. (2013). Applications of lean six sigma in an Irish hospital. Leadership in Health Services.

42. Lubowe, D., \& Blitz, A. (2008). Driving operational innovation using lean six sigma. Business Performance Management, 6(3), 10-15.

43. Mertins, K., Heisig, P., Vorbeck, J., Mertins, K., Heisig, P., \& Vorbeck, J. (2001). Knowledge management: Best practices in Europe. 
44. Michael, G. (2003). Lean six sigma for service: how to use lean speed and six sigma quality to improve services and transactions (1st Ed.). McGraw-Hill.

45. Miller, M. D., Linn, R., \& Gronlund, N. (2013). Measurement and assessment in teaching (11th ed.). Pearson.

46. Mills, A. M., \& Smith, T. A. (2011). Knowledge management and organizational performance: a decomposed view. Journal of Knowledge Management.

47. Ministry of Health. (2021). Hospitals. www.moh.gov.jo

48. Mubarik, M. S. (2015). Human capital and performance of small \& medium manufacturing enterprises: a study of Pakistan. University of Malaya.

49. Muhammad, N. A., \& Chin, J. F. (2020). Exploring knowledge management in a Lean Six Sigma organisation. International Journal of Management Concepts and Philosophy, 13(1), 20-38.

50. Murray, A., \& Sharpe, A. (2011). Human capital and productivity in British Columbia. Centre for the Study of Living Standards.

51. Newman, B. D., \& Conrad, K. W. (2000). A Framework for Characterizing Knowledge Management Methods, Practices, and Technologies. PAKM.

52. O'Reilly III, C. A., Chatman, J., \& Caldwell, D. F. (1991). People and organizational culture: A profile comparison approach to assessing personorganization fit. Academy of Management Journal, 34(3), 487-516.

53. Pasban, M., \& Nojedeh, S. H. (2016). A Review of the Role of Human Capital in the Organization. Procedia-Social and Behavioral Sciences, 230, 249-253.

54. Pepper, M. P. J., \& Spedding, T. A. (2010). The evolution of lean Six Sigma. International Journal of Quality \& Reliability Management, 27(2), 138-155. https://doi.org/10.1108/02656711011014276

55. Pinjari, H., \& Teli, S. N. (2018). Integrated approach of Six Sigma and Knowledge Management. International Journal of Scientific \& Engineering Research, 9(5).

56. Qian, Z.-W., \& Huang, G. (2017). Human capital and innovation ability in medical education: An empirical study. Eurasia Journal of Mathematics, Science and Technology Education, 13(8), 5395-5403.

57. Ranjan Senapati, N. (2004). Six Sigma: myths and realities. International Journal of Quality \& Reliability Management, 21(6), 683-690. https://doi.org/10.1108/02656710410542070

58. Raudeliūnienè, J., Davidavičienè, V., \& Jakubavičius, A. (2018). Knowledge management process model. Entrepreneurship and Sustainability Issues, 5(3), 542-554.

59. Rehman, W. ul, Asghar, N., \& Ahmad, K. (2015). Impact of Km Practices On Firms'performance: A Mediating Role Of Business Process Capability And Organizational Learning. Pakistan Economic and Social Review, 47-80.

60. Sangari, M. S., Hosnavi, R., \& Zahedi, M. R. (2015). The impact of knowledge management processes on supply chain performance: An empirical study. The International Journal of Logistics Management.

61. Sekaran, U., \& Bougie, R. (2019). Research methods for business: A skill building approach. John wiley \& sons. 
62. Shahzad, K., Bajwa, S. U., Siddiqi, A. F. I., Ahmid, F., \& Sultani, A. R. (2016). Integrating knowledge management (KM) strategies and processes to enhance organizational creativity and performance: An empirical investigation. Journal of Modelling in Management.

63. Sharma, S., \& Chetiya, A. R. (2009). Simplifying the Six Sigma Toolbox through Application of Shainin DOE Techniques. Vikalpa: The Journal for Decision Makers, 34(1), 13-30. https://doi.org/10.1177/0256090920090102

64. Sin, A. B., Zailani, S., Iranmanesh, M., \& Ramayah, T. (2015). Structural equation modelling on knowledge creation in Six Sigma DMAIC project and its impact on organizational performance. International Journal of Production Economics, 168, 105-117.

65. Snee, R. D. (2010). Lean Six Sigma - getting better all the time. International Journal of Lean Six Sigma, 1(1), 9-29. https://doi.org/10.1108/20401461011033130

66. Soliman, M., \& Saurin, T. A. (2017). Lean production in complex sociotechnical systems: A systematic literature review. Journal of Manufacturing Systems, 45, 135-148.

67. Sony, M., \& Mekoth, N. (2019). Broadening the Lean Six Sigma concept through employee adaptability: a literature review. International Journal of Productivity and Quality Management, 28(3), 279-298.

68. Spasojevic Brkic, V., \& Tomic, B. (2016). Employees factors importance in Lean Six Sigma concept. The TQM Journal, 28(5), 774-785. https://doi.org/10.1108/tqm-10-2015-0131

69. Srinivasan, K., Muthu, S., Devadasan, S. R., \& Sugumaran, C. (2016). Six Sigma through DMAIC phases: A literature review. International Journal of Productivity and Quality Management, 17(2), 236-257.

70. Subedi, B. P. (2016). Using Likert Type Data in Social Science Research: Confusion, Issues and Challenges. International Journal of Contemporary Applied Sciences, 3(2), 2308-1365. www.ijcas.net

71. Vaishnavi, V., \& Suresh, M. (2021). Assessment of readiness level for implementing lean six sigma in healthcare organization using fuzzy logic approach. International Journal of Lean Six Sigma, 12(2), 175-209. https://doi.org/10.1108/IJLSS-07-2019-0081

72. Wee, J. C. N., \& Chua, A. Y. K. (2013). The peculiarities of knowledge management processes in SMEs: the case of Singapore. Journal of Knowledge Management.

73. Worley, J. M., \& Doolen, T. L. (2006). The role of communication and management support in a lean manufacturing implementation. Management Decision, 44(2), 228-245. https://doi.org/10.1108/00251740610650210

74. Zhang, L., \& Chen, X. (2016). Role of lean tools in supporting knowledge creation and performance in lean construction. Procedia Engineering, 145, 1267-1274. 


\section{About Our Authors}

Sahoum Aljazzazen is a Doctoral Candidate in the Business administration program at the University of Pécs- Hungary. He did his MSc in Business Administration (MBA) at Balqa'a Applied University (BAU) in Jordan, and his BSc in Computer Engineering from Yarmouk University in Jordan. His main area of research revolves around quality and knowledge management with a focus on Lean Six Sigma implementation in service organizations.

Roland Schmuck is an Assistant Professor at the University of Pécs, Faculty of Business and Economics, Hungary. He has Ph.D. in economics. Currently he researches quality and actively manages it. He is the Quality Management Director and the Head of the Quality Management Committee at the Faculty. He is responsible for all quality-related courses there. $\mathrm{He}$ is the $\mathrm{PhD}$ supervisor of Sahoum Aljazzazen. 